\title{
Micro-Raman Spectroscopy of Chromosomes
}

\author{
F. F. M. de Mul, ${ }^{*}$ A. G. M. van Welie, C. Otto, J. Mud and J. Greve \\ Twente University of Technology, Department of Applied Physics, P.O. Box 217, 7500 AE Enschede, The Netherlands
}

\begin{abstract}
Raman spectra of intact chromosomes (Chinese hamster), recorded with a microspectrometer, are reported. The spectra could be assigned to protein and DNA contributions. Protein and DNA conformations and the ratio of base pairs in DNA were determined.
\end{abstract}

\section{INTRODUCTION}

In this paper we report measurements of Raman spectra of intact chromosomes, recorded with a Raman microspectrometer.

Until now, as far as we are aware, no Raman studies on (metaphase) chromosomes have been reported. Obviously the most significant reason for this lack of spectra is the relatively low cross-section for Raman scattering of the main constituents of chromosomes: DNA and proteins. The only literature concerning this subject deals with chromatin, the chromosome material in its non-condensed (non-metaphase) form, and with nucleosomes. In all cases reported, the chromatin and nucleosomes were measured in solution. ${ }^{1-9}$

Important reasons for studying the Raman scattering of chromosome material are the need for clarification of the origin of the well known band structure of chromosomes and the relation with physical diseases or mental defects such as certain types of leukaemia and mongolism. Secondly, the interaction of DNA with proteins may be very different in chromosomes compared with the laboratory situation of chromatin in solution. Moreover, the Raman scattering is a direct way of tracing DNA regions rich in adenine-thymine or cytosine-guanine. The conformation of DNA double helices can also be studied.

In this respect, the Raman spectroscopy of chromosomes and other cellular material has the following advantages over the more commonly used technique of fluorescence by staining the sample: Raman spectra are more specific, as they are line spectra, whereas fluorescence commonly gives rise to a broad smooth spectrum; the chromosome material itself is probed directly; and the danger of disturbing the DNA structure owing to intercalation of stain molecules does not exist. However, Raman spectroscopy suffers from the major disadvantage of the very low scattering intensity compared with fluorescence.

The ultimate goal of our investigations is to obtain the Raman spectra of single chromosomes and parts of these, resolved in space with a resolution of about $1 \mu \mathrm{m}$. As the cross-section for Raman scattering was expected to be very low, we decided first to record spectra of small pellets of chromosomes.

* Author to whom correspondence should be addressed.

\section{MATERIALS AND METHODS}

The chromosomes were obtained from a culture of Chinese hamster lung cells. These cells have a short cell cycle of about $12 \mathrm{~h}$. The number of chromosomes is 22 (diploid), varying in length from 2 to $10 \mu \mathrm{m}$ and in thickness from 0.5 to $1 \mu \mathrm{m} .{ }^{10}$

The metaphase chromosomes were isolated using standard growth, purification and centrifugation procedures. After the phase of growth the cells were centrifuged twice at room temperature for $7 \mathrm{~min}$ at $200 \mathrm{~g}$. This gave pellets of about $5 \times 10^{6}$ cells. Each pellet was resuspended in $1 \mathrm{ml}$ of buffer $\left(4 \mathrm{mM} \mathrm{MgCl}_{2}, 10 \mathrm{~mm}\right.$ Tris, $10 \mathrm{mM} \mathrm{NaCl} ; \mathrm{pH}=7.5$ ) and left at rest for $10 \mathrm{~min}$ at room temperature. Then $0.5 \mathrm{ml}$ of buffer containing $1 \%$ Triton X-100 was added and, after a rest period of $3 \mathrm{~min}$, the cells were squeezed 5-10 times through a $22 \mathrm{G}$ needle in order to rupture the cell walls. The cell material was centrifuged at room temperature for $5 \mathrm{~min}$ at $100 \mathrm{~g}$ in order to remove large cellular impurities. Smaller impurities were removed by centrifugation at $4{ }^{\circ} \mathrm{C}$ for $30 \mathrm{~min}$ at $900 \mathrm{~g}$. The resulting pellets contained about $5 \times 10^{7}$ chromosomes each.

According to Wray and Stubblefield, ${ }^{11}$ the contents of DNA, RNA and protein in the nucleus of a Chinese hamster cell are in the proportion 100:31:272. However, in chromosomes the RNA content is considerably lower. The content of RNA is estimated to be only $0-5 \%$ and the DNA and protein contents about 25 and $70 \%$, respectively. The total amount of DNA per metaphase cell is about $12 \mathrm{pg}$ and the amount of DNA per $\mu \mathrm{m}$ chromosome length varies from 0.05 to $0.10 \mathrm{pg}$ for the different chromosomes.

The Raman-microspectroscopic measurements were carried out using the experimental set-up described elsewhere. ${ }^{12}$ The instrumentation consisted of a Coherent $\mathrm{Ar}^{+}$laser (CR3, maximum $1.5 \mathrm{~W}$ at $514.5 \mathrm{~nm}$ ), a Nikon Optiphot microscope, a Jobin-Yvon Ramanor HG2S monochromator and an EMI-9863 photomultiplier. The optical coupling, including spatial filtering, between the various parts of the apparatus was laboratory-made. A PDP-LSI-11 on-line computer was used for storage and handling of spectra.

The samples used in the measurements were pellets of chromosomes. Before and during the measurements the pellets were immersed in the buffer solution mentioned above. In this buffer the chromosomes can be 




Figure 1. The sample reservoir.

stored for several days without noticeable changes. The pellets were deposited on a sapphire glass plate, in a transparent Perspex reservoir filled with the buffer solution. The reservoir was placed under the microscope objective (see Fig. 1). By using a transparent reservoir the sample could be observed from above with sub-stage illumination. Special precautions to fix the pellet on the sapphire were not necessary. All measurements were performed at room temperature.

Sapphire was used as a substrate because the Raman scattering intensity is much lower and the heat conductivity is considerably higher than is the case for glass. Since during the measurements the sample is completely surrounded by the buffer and the sapphire, laser powers as high as $100 \mathrm{~mW}$ with a spot diameter of about $5 \mu \mathrm{m}$ can be used without any risk of damaging the chromosomes. If the chromosome is overheated Raman measurements would be impossible, owing to an increase in the fluorescence background. After the laser irradiation of the samples no physical damage was observed and the spectra could be reproduced.

The first attempt to record a Raman spectrum of metaphase chromosomes was made with samples from a cell culture grown in polystyrene bottles and applying polystyrene sampling tubes in the centrifugation steps. However, in the spectra recorded of these samples an overwhelming contribution of the polystyrene spectrum is present, probably owing to the presence of polystyrene particulates in the pellets. It is therefore advisable not to use polystyrene for sample preparation. Bottles and tubes made of glass did not give rise to those problems.

\section{MEASUREMENTS}

With the pellets of chromosomes in water as described above, five series of meaurements were performed. The variation in the background level, probably due to (fluorescence) scattering from the pellet, the buffer and impurities in the latter, amounted to a factor of about 3 . The shape of the spectra, including the width and relative intensities of the Raman lines, could be measured in a very reproducible manner. The absolute overall intensities of the different series of measurements, however, showed a considerable variation. This

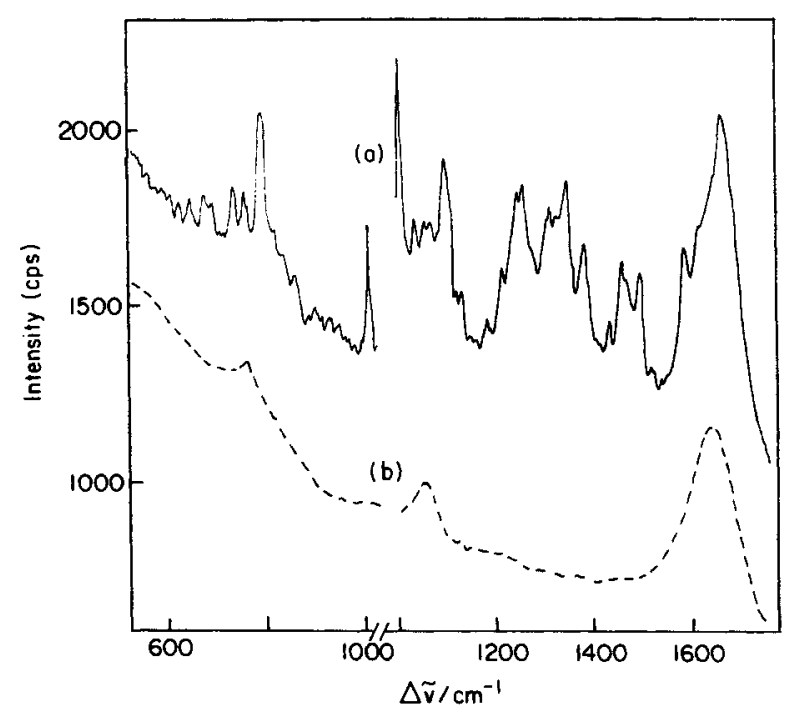

Figure 2. Micro-Raman spectrum of Chinese hamster metaphase chromosomes. Laser power at sample, $70 \mathrm{~mW}$; laser spot diameter, $6 \mu \mathrm{m}$; measuring volume, ca $150 \mu \mathrm{m}^{3}$; spectral resolution, $4.8 \mathrm{~cm}^{-1}$; scan speed, $12 \mathrm{~cm}^{-1} \mathrm{~min}^{-1}$; integration time, $20 \mathrm{~s}$. (a) Chromosome pellet; (b) buffer.

was due to differences in the absolute amount of chromosome material in the measuring volume, caused by the preparation process.

Figure 2 shows a representative plot of the measured spectra. The Raman spectra of the pellet in the buffer and of the buffer itself were recorded under the same experimental conditions. The spectrum of the pellet, shown in the Fig. 2, consists of two spectra from different runs. This shows the different overall intensities obtained because of the variation in the amount of material in the pellet, as mentioned before. A considerable part of the measuring volume of the pellet was filled with the buffer and not with chromosome material, as is clear from the spectra. In order to estimate the relative amount of this part, we considered the intense band at about $1660 \mathrm{~cm}^{-1}$. This band is expected to be caused by the amide I-vibrations of the proteins and the $\mathrm{C}=\mathrm{O}$ stretch of the DNA bases. However, as can be seen in the spectrum of the buffer, the water solvent also contributes to this scattering with a broad band centred at $1640 \mathrm{~cm}^{-1}$. By comparing the relative intensities of the pellet spectra and the buffer spectra, and taking also the Raman results of Thomas $e t a l .^{9}$ on chicken erythrocyte chromatin into account, the relative amount of the buffer in the measuring volume could be estimated to be $0.7 \pm$ 0.1 .

A typical spectrum, obtained after subtraction of that of the buffer, taking the above-mentioned factor of $0.7 \pm 0.1$ into account, is shown in Fig. 3. The background in this spectrum is probably due to 'polluting' contributions from organic material, e.g. remainders of the cells or impurities in the buffer. Although we tried to remove those particles from the sample, by the methods indicated above, not all particles could be removed. This caused considerable variations in the background level of the different measurements, as can be seen in Fig. 3, in which a spectrum is shown which was measured in two parts, with two different samples.

In order to decide which lines in the spectra could still be considered as being significant, the noise level 


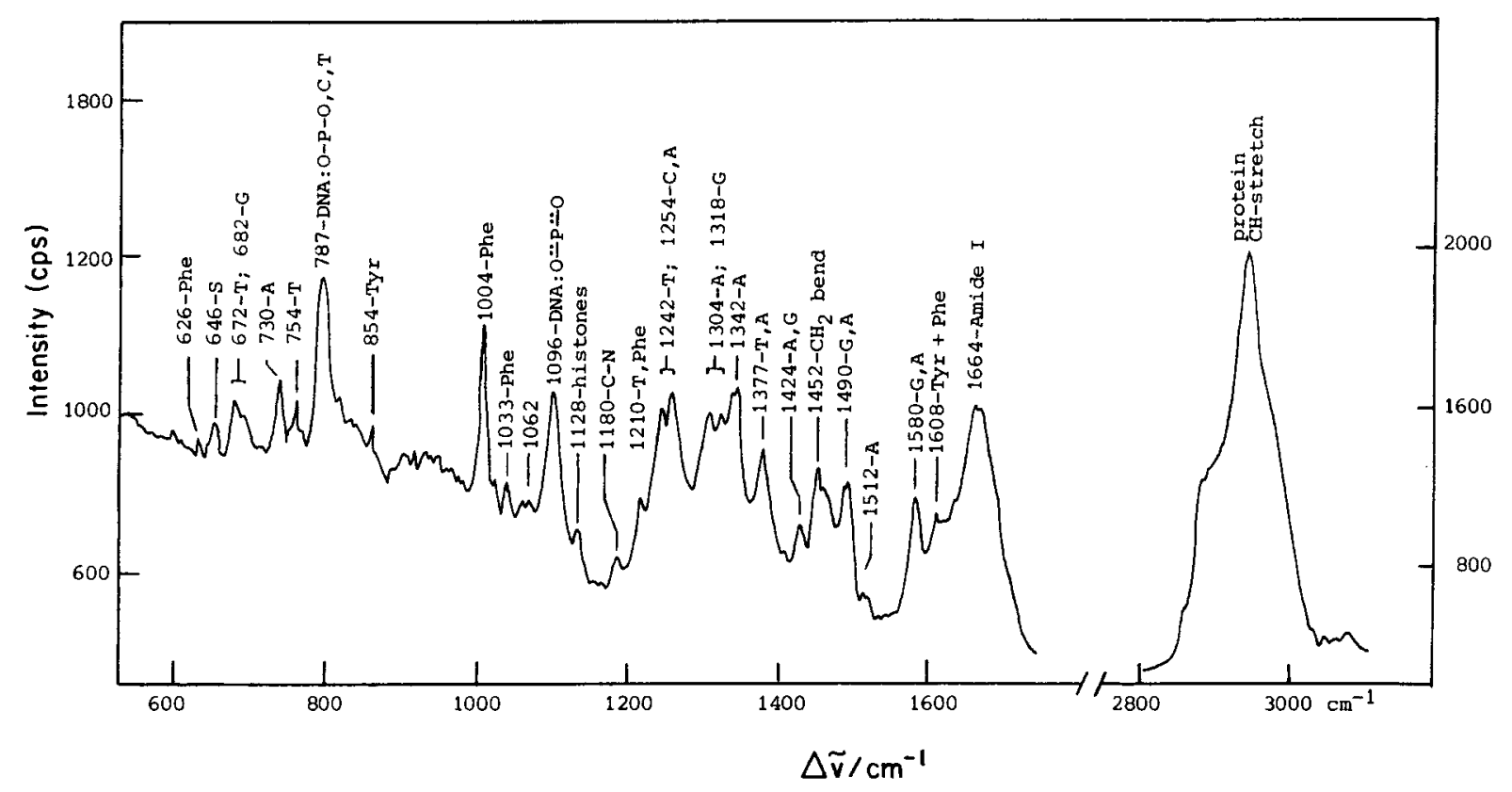

Figure 3. Micro-Raman spectrum of Chinese hamster metaphase chromosomes; background and buffer subtracted. Laser power at sample, $70 \mathrm{~mW}$; laser spot diameter, $6 \mu \mathrm{m}$; measuring volume, ca $150 \mu \mathrm{m}^{3}$; spectral resolution, $4.8 \mathrm{~cm}^{-1}$; scan speed, $6 \mathrm{~cm}^{-1} \mathrm{~min}^{-1}$; integration time, $20 \mathrm{~s}$. Assignments: $\mathrm{S}=$ sapphire; $C, A, G, T=D N A$ bases cytosine, adenine, guanine and thymine, respectively; Tyr, Phe = protein lines of tyrosine and phenylalanine, respectively.

has to be calculated, taking the sampling time of $20 \mathrm{~s}$ at each spectral position into account. As the count rate amounts to about $1500 \mathrm{cps}$, this noise level turns out to be $\sqrt{1500} / \sqrt{20} \approx 10 \mathrm{cps}$. We shall discuss further only those lines which have peak intensities exceeding $50 \mathrm{cps}$, which are well above the noise level.

\section{DISCUSSION}

In this section an explanation will be given for all relevant lines in the spectra, related to literature spectra of DNA, proteins and chromatin. All spectra published so far refer to suspension samples, measured with conventional normal or resonant macro Raman techniques.

In Fig. 3 the significant lines are indicated with the corresponding assignments. Almost all lines could be assigned to the DNA or the protein contents of the chromosomes.

\section{Protein lines}

Since most amino acids are poor Raman scatterers, in the spectra of histone proteins published so $\mathrm{far}^{3,7-9}$ only a few lines could be assigned to individual amino acids. For example, the histone protein $\mathrm{H1}$, containing lysine $(26.8 \%)^{13}$ does not show any lysine line in the spectrum. ${ }^{8}$ Other amino acids frequently present in histone proteins, such as glycine, alamine and arginine, are poor Raman scatterers also. However, some vibrations of phenylalanine (Phe) and tyrosine (Tyr) have a high Raman scattering cross-section. ${ }^{8}$ The ring breathing mode of Phe at $1004 \mathrm{~cm}^{-1}$ can be detected even in the spectrum of the histone $\mathrm{H} 2 \mathrm{a}$, containing only about $1 \%$ Phe (one residue).

In Fig. 3 some lines could be assigned to Phe and Tyr. The contribution of Phe is even larger than would be expected on the basis of the sum of the individual histon contributions, taking into account the relative contents of the various histones. ${ }^{7,8}$ This is concluded from the relative intensities of the Phe line at $1004 \mathrm{~cm}^{-1}$ and the $\mathrm{CH}$ bending mode at $1452 \mathrm{~cm}^{-1}$, which are in the ratio $(1.6 \pm 0.2): 1.0$, compared with the literature spectra of the individual histones, ${ }^{5,14}$, the ratio being 0.6 . This leads to the conclusion that in our metaphase chromosome samples a considerable contribution of non-histone proteins should be present. In this calculation we assumed equal contributions in mass of the five histones to the spectra of the chromosomes. We also made use of the observations of Albers, ${ }^{15}$ indicating that the $\mathrm{CH}$ bending in DNA gives rise to a negligible contribution to the spectrum only.

From the Raman spectra the conformation of the proteins can be obtained. In our spectra the Raman band at $1660 \mathrm{~cm}^{-1}$ is broad and it can be shown that it consists of two contributions, centred at 1660 and $1670 \mathrm{~cm}^{-1}$. The $1660 \mathrm{~cm}^{-1}$ line refers to an $\alpha$-helix conformation ${ }^{16}$ and the $1670 \mathrm{~cm}^{-1}$ line may correspond to either a $\beta$-sheet or a random coil conformation. However, a $\beta$-sheet conformation also should give rise to an intense line at $1240 \mathrm{~cm}^{-1}$. From the absence of this intense line it can be concluded that the protein conformation in these chromosomes is a combination of $\alpha$-helix and random coil. This is in agreement with the literature on histones. ${ }^{9}$

The Raman line at $2800-3000 \mathrm{~cm}^{-1}$ is caused by the $\mathrm{CH}$ stretch vibration. The intensity is mainly caused by the proteins; the $\mathrm{CH}$ stretch of the DNA is of minor importance in this spectral region. 


\section{DNA lines}

All lines measured in DNA fibres or crystals appear to be present in the chromosome spectra also. For the characterization of the conformation of the DNA we used as fingerprints lines of 811,835 and $870-880 \mathrm{~cm}^{-1}$ for the presence of the $A, B$ and $C$ conformation respectively. Recently it was suggested ${ }^{16,17}$ that part of the DNA in a chromosome could be in a left-handed $Z$ conformation. Until now only a Raman spectrum of an artificial polynucleotide $[$ poly-d $(G-C)$, poly-d(G-C)] has been published. This spectrum shows a line at $625 \mathrm{~cm}^{-1}$, which is not present in $A, B$ or $C$-DNA. Although there is a line at $625 \mathrm{~cm}^{-1}$ in the present spectra, we assume that it is probably due to Phe, and not to $Z$-DNA, since the relative intensities of the 625 and the $1004 \mathrm{~cm}^{-1}$ lines of Phe agree with those measured in our laboratory with pure Phe. ${ }^{18}$ Also other characteristics of a $Z$-helix form as suggested [for poly$\mathrm{d}(\mathrm{G}-\mathrm{C})$, poly-d(G-C)] (low $1096 \mathrm{~cm}^{-1}$ line, disappearance of the $682 \mathrm{~cm}^{-1}$ line) are absent.

The presence of the shoulder at $835 \mathrm{~cm}^{-1}$ and the absence of lines at 811 and $875 \mathrm{~cm}^{-1}$ indicate that the DNA is mainly in the $B$ conformation. This is in agreement with literature spectra of chromatin. ${ }^{2,6,9}$

From the relative intensities of the $672 \mathrm{~cm}^{-1}$ line (thymine, T) and the $682 \mathrm{~cm}^{-1}$ line (guanine, G) the relative base-pair percentages of adenine-thymine (AT) and cytosine-guanine (CG) can be calculated. In calf thymus DNA the AT and CG contents are 56 and $44 \%$ respectively. ${ }^{19}$ The ratio of the line intensities $I(672) / I(682)$ then amounts to about $1.0 .^{15,19}$ In our spectra this proportion is $1.6 \pm 0.1$, which leads to AT and CG contents of $62 \pm 2$ and $38 \pm 2 \%$, respectively. This ratio of $1.6 \pm 0.1$ is higher than that reported for chromatin in various mammalian organisms $(1.2-1.5) .^{20}$

Measurements performed in our laboratory, ${ }^{15}$ with DNA fibres as a sample, a laser power at the sample position of $0.8 \mathrm{~mW} \mathrm{\mu m}^{-2}$, a measuring volume of

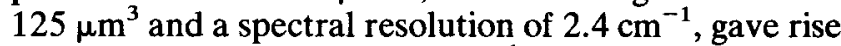
to $250 \mathrm{cps}$ in the line at $1096 \mathrm{~cm}^{-1}(\mathrm{O} \cdots \mathrm{P} \cdots \mathrm{O}$ backbone stretch). In the present measurements, with a measuring volume of $300 \mu \mathrm{m}^{3}(6 \mu \mathrm{m}$ diameter and $10 \mu \mathrm{m}$ focal depth), a spectral resolution of $4.8 \mathrm{~cm}^{-1}$ and with $71 \mathrm{~mW}$ power at the sample, we measured $360 \mathrm{cps}$ in the $1096 \mathrm{~cm}^{-1}$ line. Using a DNA content in the chromosomes of $30 \%$, we again calculate the proportion of chromosomes in the pellet to be $30 \%$, leaving $70 \%$ for the buffer, as was calculated before on other grounds.

\section{Interactions of DNA and protein}

Recently in the Raman spectrum of rat liver chromatin a splitting of the $1096 \mathrm{~cm}^{-1}$ DNA backbone stretch was observed. ${ }^{6}$ This was attributed to presumed differences in the DNA environments (DNA around the nucleosomes and DNA between the nucleosomes). This splitting was not observed in formerly reported chromatin spectra. ${ }^{2}$ We did not find a splitting of this $1096 \mathrm{~cm}^{-1}$ line in the spectra of our chromosome samples either.

From calf thymus chromatin measurements of Goodwin and Brahms, ${ }^{2}$ it was concluded that the intensity of the guanine line at $1490 \mathrm{~cm}^{-1}$, decreases with respect to the $1096 \mathrm{~cm}^{-1}$ line in the presence of an increasing amount of non-histone proteins. The $1490 \mathrm{~cm}^{-1}$ line corresponds to the N7-C8 stretch of guanine, which may interact with amino acid side-chains of non-histone proteins. In the spectra of nucleosome suspensions, not containing non-histones, the $1490 \mathrm{~cm}^{-1}$ intensity is equal to that in pure DNA. ${ }^{2}$ It was concluded that $I(1490) / I(1096)$ varied from 1.2 to 0.6 and 0.2 , with relative concentrations of non-histones and histones of $0,0.1$ and 1 , respectively.

From our spectra we estimate $I(1490) / I(1096) \approx 0.8$. However, in calf thymus DNA the proportion of CG pairs is $56 \%$, whereas in Chinese hamster DNA this proportion is $38 \%$. This should correct the abovementioned result of 1.2 to 0.8 , which would indicate that the amount of non-histone proteins is very small. However, this contradicts the conclusion mentioned earlier, on the basis of the Phe line intensities. On the other hand, from various sources it is known that the spectral position and the intensity of the Phe line at $1004 \mathrm{~cm}^{-1}$ does not vary much with the binding situation of Phe. Probably this particular comparison of spectra of different samples (chromatin vs metaphase chromosome) and of different animal origin is not valid.

\section{CONCLUSIONS}

From the above studies on the Raman spectra of intact metaphase chromosomes the following conclusions can be drawn: using Raman microspectroscopy, it is feasible to record good spectra of pellets of intact chromosomes in short times with relatively low laser powers; the chromosome pellet remains intact under intense laser irradiation, when immersed in the buffer (mostly water); the spectra appear to be sum spectra of the individual constituents: DNA and proteins; apart from variations in the background level (probably due to polluting particles left behind after the centrifugation procedure), the spectra are very reproducible; the Phe $1002 \mathrm{~cm}^{-1}$ line intensities indicate a considerable contribution of nonhistone proteins to the spectra; the chromosome protein conformation is a combination of $\alpha$-helix and random coil; the chromosome DNA is mainly in the $B$ conformation; the ratio of $\mathrm{AT}$ and $\mathrm{CG}$ base pair contents in the chromosome is $1.6 \pm 0.1$; and no splitting of the $1096 \mathrm{~cm}^{-1} \quad \mathrm{O} \cdots \mathrm{P} \cdots \mathrm{O}$ DNA stretch vibration was observed.

In conclusion, as spectra of small pellets $\left(\mathrm{ca} 100 \mu \mathrm{m}^{3}\right)$ of chromosomes can be recorded with a normal Raman micro-instrument in reasonably short times, the prospects of measuring a single chromosome or a single section of a chromosome are relatively good, probably even without the application of CARS or SERS.

\section{Acknowledgements}

This work was supported in part by the STW (Stichting voor Technische Wetenschappen) and the Pieter Langerhuizen Lambertuszoon Fonds. 


\section{REFERENCES}

1. K. M. Ervin, E. Koglin, J. M. Sequaris, P. Valenta and H. W. Nurnberg, J. Electroanal. Chem. 114, 179 (1980).

2. D. C. Goodwin and J. Brahms, Nucl. Acids Res. 5, 835 (1978).

3. D. C. Goodwin, J. Vergne and J. Brahms, J. Am. Chem. Soc. 18, 2057 (1979).

4. E. Koglin, J. M. Séquaris and P. Valenta, J. Mol. Struct. 79, 185 (1982).

5. J. M. Séquaris, E. Koglin, P. Valenta and H. W. Nurnberg, Ber. Bunsenges. Phys. Chem. 85, 512 (1981).

6. H. Klump, E. D. Schmid and M. Moschallski, in Proceedings of VIIIth International Conference on Raman Spectroscopy 1982. p. 727, Wiley Heyden, Chichester (1982).

7. R. Savoie and J. J. Jutier, in Proceedings of VIIIth International Conference on Raman Spectroscopy, 1982, p. 749. Wiley Heyden, Chichester (1982)

8. J. G. Guillot, M. Pezolet, D. Pallotta, Biochim. Biophys. Acta 491, 423 (1977)

9. G. J. Thomas, B. Prescott and D. E. Olins, Science 197, 385 (1977).

10. H. Burki, T. J. Regimbal and H. C. Mel, Prep. Biochim. 3, 157 (1973).
11. W. Wray and E. Stubblefield, Exp. Cell. Res. 59, 469 (1970).

12. (a) H. Buiteveld, F. F. M. de Mul, J. Mud and J. Greve, Appl. Spectrosc., in press; (b) F. F. M. de Mul, H. Buiteveld, J. Lankester, J. Mud and J. Greve, J. Human Pathol., in press.

13. E. M. Bradbury, N. Maclean and H. R. Matthews, DNA Chromatin and Chromosomes. Blackwell, New York (1981).

14. M. G. Albrecht and J. Creighton, J. Am. Chem. Soc. 99, 215 (1977).

15. B. Albers, Twente University of Technology, Enschede, Internal Report (1983); personal communication.

16. T. J. Thamann, R. C. Lord, A Wang and A Rich, Nucl. Acids Res. 9, 5443 (1981).

17. A. Nordheim, M. L. Pardue, E. M. Lafer, A. Möller, B. D. Stollar and A. Rich, Nature (London) 294, 417 (1981).

18. C. Otto, unpublished work.

19. S. C. Erfurth and W. L. Peticolas, Biopolymers 14, 247 (1975)

20. G. D. Fasman (Ed.), Handbook of Biochemistry and Molecular Biology, 3rd ed. CRC Press, Cleveland, Ohio (1976).

Received 30 November 1983 